\title{
Children's learning processes using unsupervised "hole in the wall" computers in shared public spaces
}

\author{
Ritu Dangwal and Preeti Kapur \\ NIIT Institute of Information Technology, India
}

\begin{abstract}
Earlier research by Mitra and colleagues on the use of computers by young children revealed that children are able to learn basic computing skills irrespective of their social, cultural, intellectual and religious backgrounds (Mitra \& Rana, 2001). The present paper is an attempt to identify the varied aspects of a learning environment that impact upon the learning process enabled by "hole in the wall" computers. The study covers 250 children in the age group 8 to 14 years using qualitative and anecdotal evidence given by children and research consultants in the field. The evidence indicates that the environment in which the child learns is of importance for it brings together a host of different yet interrelated aspects of learning. The findings suggest a pedagogic tool for alternative methods to teaching in school settings, and strengthen the view that students should be engaged in a thinking curriculum, wherein everyone learns from everyone else, and no student is deprived of the opportunity for making contributions and appreciating the contributions of others.
\end{abstract}

\section{Background}

The first "hole in the wall" experiment was conducted in Kalkaji, a suburb of New Delhi, India, wherein a computer was connected to the Internet and embedded into a brick wall near a slum (Education Guardian, 2000; Mitra \& Rana, 2001; Frontline/World, 2002; Mitra, 2003; Mitra, Dangwal, Chatterjee, Jha, Bisht \& Kapur, 2005). This experiment was followed by a series of such experiments at places in and around Delhi. It was reported that most of the urban slum or rural children were able to use the computers to browse, play games, create documents and paint pictures within a few days. Subsequent to these findings, "hole in the wall" computers were set up in a large scale in 22 rural and urban slum locations across India. Similar results were reported through field observations as well as through the Graphical User Interface (GUI) Icon Association Inventory (IAI) test (Mitra, 2003; Dangwal, Jha, Chatterjee \& Mitra, 2005) administered to children. Observations across locations show a learning process of random exploration, collaboration, discovery, vocabulary construction, generalisation, practice and peer tutoring (Inamdar, 2004).

Thus, it was observed that, even in the absence of any direct input, mere curiosity led groups of children to explore, which resulted in learning. This, coupled with minimal input from peers, or from someone familiar with the situation, helped the children learn more. This led us to believe that any learning environment that provides an adequate level of curiosity can cause learning among groups of children. The children's desire to learn, along with their curiosity and peer interaction, drives them to explore the environment in order to satisfy their inquisitiveness. As children explore their environment, they relate their new experience to their previous experience and 
thereby new learning takes place (Mitra et al. 2005). "Hole in the wall" experiments illustrate a new pedagogic method that uses the learning environment to generate an adequate level of motivation to induce learning in groups of children, with minimal or no intervention by a teacher.

In the present paper, an attempt is made to understand the group dynamics of this learning environment. In a traditional sense, the "hole in the wall" computer (sometimes termed as "the learning station") is the stimulus and the learning by the children is the response. The paper attempts to seek an understanding of "why" and "how" the learning is happening.

\section{The sample}

The sample was taken from 17 locations all across India where "hole in the wall" computers are located. A total number of 250 children were selected for study. These children were regular users of the "hole in the wall" computers. Their ages ranged from 8-14 years with an average age of 10-11 years. The location of the sites is both rural and urban slums of India. The observations were undertaken in four zones (Table 1) during 2003-05.

Table 1: Zone location

\begin{tabular}{|l|l|}
\hline South Zone & 2 States - Karnataka and Tamil Nadu \\
\hline North Zone & 3 States - Uttaranchal, Jammu and Kashmir, Uttar Pradesh \\
\hline East Zone & 1 State - West Bengal \\
\hline West Zone & 2 States - Rajasthan and Maharashtra \\
\hline
\end{tabular}

The children came from diverse ethnic and cultural backgrounds. They were typically Hindus, Muslims, and Christians and even within a given community they were from different castes. All these children studied at the local elementary school level (below grade 8) and were enrolled in regular schools, mostly in government schools. The backgrounds of the parents of these children were equally diverse; they were either working on daily wages or were farmers, shopkeepers, auto drivers, etc. With regards to education, fathers were educated to 8th grade on average, whilst mothers mostly were illiterate.

\section{Method}

In order to map the various aspects of the learning environment in the "hole in the wall" experiment, a multi-pronged strategy was employed. Three different sources were employed to assess learning:

- Interviews

- Research consultants (RCs) daily observation reports

- Children's diaries

These three different, yet complementary methods, help in understanding the various perspectives of the learning environment - what are the children learning; how are they learning; from whom are they learning and how do they feel about the learning station and their experiences at the "hole in the wall" computers or the learning stations. 


\section{Interviews}

Extensive in depth interviews were undertaken with children who visited the learning station. The interviews were assisted by the team of researchers extending over a period of three years. The interviews were conducted in various situations so as to cover the entire range of information regarding the learning environment. Three situations were identified for conducting interviews:

- Immediately after the children had completed playing on the computer and were leaving the computers

- While making personal visits to their homes to talk to the children

- While causally talking to children about their experiences at the learning station

It is to be noted that the interviews were held in an informal and unstructured setting. Yet, the focal issue is to capture the various elements arising from using "hole in the wall" computers. In addition to the interviews, observations made by the research team were recorded; this provided an insight into the nuances of the learning environment, especially noting what the children had to say about their experiences. Where possible, audio recordings were made, for subsequent transcription and documentation in English. Typically, the conversation was captured in the regional language. Later, these documents were translated into English in our Head Office. Not all children coming to the computers were interviewed; children frequenting "hole in the wall" computers were randomly selected. Interestingly, some children were bold and enterprising and approached directly for the interview; while others had to be approached, as they were shy and hesitant. In total, approximately 150-160 children were interviewed.

\section{RC's daily observation report}

The objective for maintaining daily observation by research consultants was to document and analyse the developmental learning process at the "hole in the wall" computers. This documentation provided us with in depth yet diverse perspectives.

The RCs observed the children at the learning station for a period of nine months and maintained a daily diary in English for the entire nine months. They were informed that observations of what children did at the computer were more critical than the language (English). They were asked to send these diaries as soft copies every week to our Head office in Delhi. No specifications were given in terms of the number of pages to be written in the diary.

To maintain consistency, the diaries had a specific format. To illustrate, two excerpts are given in Tables 2 and 3. These examples are from the research consultant's daily observations at a site in Karnataka, South Zone (Table 1).

\section{Research consultant's role}

At each learning station, there was one dedicated RC for the whole day. The RC observed and made notes for at least 2 hours every day on what was happening at the learning station. The RC would observe randomly; sometimes in the morning, in the afternoons and in the evenings. This exercise took care of any pattern that emerged as a result of "day" being a factor in the usage. Interestingly, no pattern was observed and children were found to use the computer whenever available. In total, there were 
17 observational diaries from the 17 sites, for each day for a period of nine months. By the end of the research period, we had approximately 279 diaries from each RC. Overall, there were 4743 diaries from all the sites.

Table 2: Diary excerpt 1

\begin{tabular}{|l|l|l|l|l|}
\hline $\begin{array}{c}\text { Date and } \\
\text { time }\end{array}$ & $\begin{array}{l}\text { No. of } \\
\text { children }\end{array}$ & Application & \multicolumn{1}{|c|}{ Action } & \multicolumn{1}{c|}{ Remarks } \\
\hline $\begin{array}{l}\text { 21 Feb 03 } \\
\text { (1.00 pm) }\end{array}$ & $\begin{array}{l}\text { Boys: 03 } \\
\text { Girls: 01 } \\
\text { Total: 04 }\end{array}$ & Notepad & $\begin{array}{l}\text { Kirana opened } \\
\text { note pad by } \\
\text { pressing start } \\
\text { + program } \\
\text { note pad }+ \\
\text { enter key. }\end{array}$ & $\begin{array}{l}\text { He told that he has opened note pad. With } \\
\text { this, he can type his name and address and } \\
\text { also he can save his file. He has learnt this is } \\
\text { learned form Ravi TR. When the note pad } \\
\text { appeared he changed the font color and font } \\
\text { size by clicking respective options. Then he } \\
\text { typed his and his friends address. He is } \\
\text { finding it a little easy to locate the letters. } \\
\text { After finishing writing he went to file option } \\
\text { and selected save as option and clicked red } \\
\text { touch pad. He typed his name in file name } \\
\text { column and pressed over save option he told } \\
\text { that he has saved his file. }\end{array}$ \\
Internet & $\begin{array}{l}\text { Kirana opened } \\
\text { internet by } \\
\text { directly } \\
\text { clicking over } \\
\text { internet option } \\
\text { on desktop. }\end{array}$ & $\begin{array}{l}\text { He told that his intention is to open kannada } \\
\text { song. He also told that he don't know the } \\
\text { address and will ask others. When the page } \\
\text { opened he asked aruna and aruna told him } \\
\text { the spelling, he typed www.akashaudio.com } \\
\text { and pressed enter key, again he asked aruna } \\
\text { what should he press, he told him to press } \\
\text { new release. He took the cursor over new } \\
\text { release and pressed red touch pad. Again he } \\
\text { asked him and he told him to press over } \\
\text { Appu. He took the cursor over appu and } \\
\text { pressed red touch pad. When the list of songs } \\
\text { appeared, he clicked over first song and } \\
\text { waited for a while and got the song, he was } \\
\text { delighted and other children rushed towards } \\
\text { him. He continued it for few minutes. }\end{array}$ \\
\hline
\end{tabular}

The RC's diaries helped us gain insight into some of the very basic questions: typical size of the group, number of children using, any gender differences observed, applications most frequently used, and how the groups helped navigate across applications.

It was clearly observed that learning was happening in groups. These groups were typically heterogeneous in nature. In other words, they were a mix of boys and girls with varying age difference. For example, a group could consist of 6 children, three girls and three boys. The age range of this group could be between 8-14 years. A typical group size would vary from 3 to 6 (at the maximum). Interestingly, in all the rural villages, where "hole in the wall" computers are installed, no gender differences have been observed. This could be attributed to the very nature of the place. For example, a village is a close knit community and nobody feels threatened; even government schools in these villages are co-educational. However, as we move towards urban slums, we find no gender differences till the girl reaches the puberty age. Gender differentiation starts to begin from 13-14 years onwards. This is when 
parents do not encourage their daughters to work at the learning station with boys. Interestingly, in urban slums, government schools have different timings for boys and girls.

Table 3: Diary excerpt 2

\begin{tabular}{|c|c|c|c|c|}
\hline $\begin{array}{c}\text { Date and } \\
\text { time }\end{array}$ & $\begin{array}{l}\text { No. of } \\
\text { children }\end{array}$ & Application & Action & Remarks \\
\hline $\begin{array}{l}7 \text { October } \\
2003 \\
(4 \mathrm{pm})\end{array}$ & $\begin{array}{l}\text { Boy: } \\
\text { 1. Gangadara } \\
\text { Girls: } \\
\text { 1. Sowmya } \\
\text { 2. Shruthi } \\
\text { 3. Rajani }\end{array}$ & $\begin{array}{l}\text { 1. Sowmya } \\
\text { was playing } \\
\text { zeek part } 1 \\
\\
\text { 2. She know } \\
\text { windows } \\
\text { media player, } \\
\text { paint. } \\
\text { Notepad, 3D } \\
\text { pinball, CD, } \\
\text { electricity etc. }\end{array}$ & $\begin{array}{l}\text { 1. She pressed start } \\
\text { button and followed } \\
\text { program and directly } \\
\text { went to the game and } \\
\text { pressed enter button. } \\
\text { 2. By moving the curser } \\
\text { over start option and } \\
\text { pressed it by using red } \\
\text { joystick, then she went to } \\
\text { volume and drag the } \\
\text { volume button by } \\
\text { pressing red and green } \\
\text { joystick simultaneously. }\end{array}$ & $\begin{array}{l}\text { She told that while } \\
\text { dragging she has to keep } \\
\text { the red button under } \\
\text { press otherwise she } \\
\text { couldn't drag. After some } \\
\text { time she has closed the } \\
\text { program by pressing Alt } \\
+ \text { F4 keys. She told that } \\
\text { this is Alt }+ \text { F4 button and } \\
\text { shortest way to close the } \\
\text { program. }\end{array}$ \\
\hline $\begin{array}{l}9 \text { October } \\
2003 \\
(1 \mathrm{pm})\end{array}$ & $\begin{array}{l}\text { Girls: } \\
\text { 1. Saumya } \\
\text { 2. Sunitha }\end{array}$ & $\begin{array}{l}\text { 1. Saumya was } \\
\text { working on } \\
\text { computer and } \\
\text { opened } \\
\text { Outlook } \\
\\
\text { 2. Sunitha } \\
\text { opened } \\
\text { windows } \\
\text { media player }\end{array}$ & $\begin{array}{l}\text { 1. By pressing Start + } \\
\text { program +outlook } \\
\text { express + enter key. } \\
\text { She pressed address and } \\
\text { typed her name in the } \\
\text { respective column. } \\
\text { 2. By pressing tab button } \\
\text { she selected the option. }\end{array}$ & $\begin{array}{l}\text { Saumya told that first } \\
\text { time she is opening this } \\
\text { program, she had no idea } \\
\text { what she had to do. She } \\
\text { showed me the column } \\
\text { name and told that this is } \\
\text { where you put your } \\
\text { name. She also told that } \\
\text { she wanted to know more } \\
\text { about computers. } \\
\text { Sunita told that this is like } \\
\text { a mouse, she can open the } \\
\text { program by using it. She } \\
\text { also said that in case of } \\
\text { absence of mouse she can } \\
\text { use the tab keys to open } \\
\text { the program. She had } \\
\text { learnt all this with the } \\
\text { help of her friend Saumya } \\
\text { and herself by doing it } \\
\text { accidentally. One day she } \\
\text { was pressing tab key and } \\
\text { observed a box moving } \\
\text { forward, she pressed } \\
\text { enter key and observed } \\
\text { the changes, then after } \\
\text { she used tab key to select } \\
\text { the option. }\end{array}$ \\
\hline
\end{tabular}

\section{Children's diaries}

Children were asked to maintain personal diaries voluntarily. Flexibility was give to them to write "as and when" they wanted to pen down their thoughts. They shared 
things like: what they have learnt, how they learnt it and what they felt. The entries made by children are periodic in nature spread over nine months. As stated earlier, not all children opted to writing the dairies; we have a minimum of two children maintaining a dairy. Hence, overall, we have 34 diaries written by children.

Table 4: Child's diary excerpt

Kiran Kumar (male, 10 years, 5th class) Site: Karnataka, South Zone

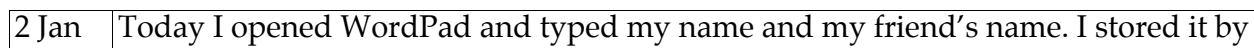

03 pressing over file button and typed my name in the file name column, and then I pressed save button to save the file.

In media player, I pressed play option to start the music and pressed F4 button to enlarge the screen. I learnt this by observing others. I like this because it contains music,

10 Jan I opened WordPad by pressing Start + program + WordPad + Enter key. When WordPad 03 opened, I went to number column and selected 26 and pressed red button, then I went to color and selected red color to write my name. I like this because here I can write my name in different colors. After writing, I closed the file by pressing Alt + F4 button. .I learnt this by observing others.

17 Jan I opened Internet and started playing music. I learnt this by observing Somesha, I

03 opened Internet by directly clicking over Internet options on the main page and pressed enter key to open then typed www.apbkdh.com and again pressed enter button.

I got one song with three pictures. Then, I clicked on audio. I got a music list and selected the second song and pressed red mouse to start the music. I opened three songs. Presently, I don't want others help to open Internet.

25 Jan Today, I opened kid match. Here, I have to match the pictures. First, I took the arrow on

03 the picture then pressed the red mouse. Then I took it in to another picture. After finishing the game, I heard some music it is very sweet to listen.

Then, I opened Hindi songs by typing www.apbkdh.com and pressed enter key. I learnt this myself. Two pictures appeared, I took the first picture and clicked the red mouse. A list of songs appeared. I clicked on the first song and after some times I heard the song and it is excited me very much.

$25 \mathrm{Feb}$ I opened kid match by pressing Start + Program + Games + Kid match + Enter key. I

03 learnt it from Somesha, When the game opened, I took the Arrow over one picture and took the arrow over other picture and pressed enter key to match each other. Sometimes, I succeeded and sometimes I failed.

Then I went to Minesweeper. This is bomb game. I learnt it from Somesha. Here, I pressed over columns and tried to arrange the numbers. If I am wrong a bomb explodes and the game ends. I like this, because it contains bomb.

After that, I opened www.prajavani.net. I opened this by pressing on Internet options in main page. I learnt it from Somesha. I like this because we can read daily affaires. Today, I read all the news and clicked over headlines to see detailed news.

From the above two excerpts, it is clear that children sometimes work on their own and for some applications take help from their friends. They like working on WordPad, Internet, music and educational games, like Galactic Multiplication. It appears that children are very clear about "what they want to learn", "why they want to learn" and from "whom they want to learn from".

Analyses of children's diaries revealed the following aspects of learning from "hole in the wall" computers:

- Learning of computer usage, that is, to understand the strategy adopted by children in learning computer skills.

- Group dynamics, that is, the interplay between the learning style and the identification of group leaders and children at the "hole in the wall" computers. 
Analysis of children's diaries cited "leaders" who were actively engaged in working at the computers, and "observers" who gave inputs when required.

To evaluate consistency between an RC's observations and children's dairies, notes were randomly compared for each site, to check accuracy in the name of the child and application used. One could also, track "leaders", "observers", the most frequently used application and the peer structure around the leader. This mechanism served two purposes: to study the group dynamics; and also, to check the authenticity of the data.

Table 5: Child's diary excerpt

Basappa J (male, 11 years, 6th class), Site: D'Salundi, South India

01 Feb I learnt to open other places to see other places. In order to do that, we need to press on

03 tour. I also learnt to do maths. To go to that, we have to go to programs- galatic multiplication and I know to solve it. I liked it very much. I learnt to write names and I can write your name and mine too. To go to paint, we have to go to start button, accessories \& paint and press enter. I have filled colours with brush.

I wrote my names and filled colours in it. I wrote it inside the box pressing on square box. To go to paint, we have to press start button+ Accessories+ Paint. I typed my name and saved it in my name. This way it never goes and will be inside the computer. I also know how to type www.Prajavani.net.This is Kannada news, we open it to read. I have played skeleton game. In that, we have to join the bones to animals. If we type www.akashaudio.com we can hear Kannada songs in it.

10 Feb I like to work with Malaiah, Nagarathana and Avinash. We share our time with each 2003 other and while one of us works the others watch. I play many games like: shoe matching, skeleton game, electricity connecting game, and I have also done painting and saved it. I opened newspaper and music of kannada film; this comes from opening the Internet. I taught the skeleton game to Nagarathana, which I learnt it from Naveen. From Prashanth, I learnt to open Internet. While, Avinash learnt painting from me.

Today, I wrote my name inside the computer and played games. I also love painting my name in shining letters with different colours. I also play the skeleton game in which you have to join the bones. I play music, type our poem in word pad and after writing it, save it and calculate sums by taking calculator. I like the following games: flower eating games, sending letters from Internet, playing film songs and sending greetings also. I like to work with Prashanth and Naveen as they know many things.

$21 \mathrm{Feb}$ I have painted the pictures with colors in computer and also filled colors to the pictures, 2003 opened MS power point and typed my name and gave many designs and sound to it, type my name inside the computer And also change the computer pictures. Open Internet and see news paper and also open yahoo and type my name and open My letter box. Play current game and monkey game, English games and alphabet game and also type the colors and join the pieces of pictures given. Opened India map and also seen many Karnataka and Mysore pictures. I opened Hindi letters. And also set the same set of pictures which gives scores to it. I like to do with Prashanth and Navven.

10 In paint I drawn my name and my address also and I saved that and I learnt it from

Mar the Ravindra. Zeek the geek -1 is a very nice game for me and it is very interesting to

2003 play. I am fond of music have and also cartoon game. I like to do the Volvo game that is called as the Algulimane.

When I came to work in the computer, elders were asking me to how to play to Game. I taught for so many elders.

\section{Results}

Data gathered from the three sources, RC's observations, children's diaries and interviews with children revealed various aspects of the learning environment. It is 
pertinent to note that although these issues are discussed as salient issues, it is the interplay of all these aspects together that provide the composite learning environment at "hole in the wall" computers.

Results from the research conducted over the past four years focus clearly on two aspects of learning:

i. Why are children learning? - the role of age and preparedness for learning and the context, i.e. the "hole in the wall" computers acting as a novel stimulus.

ii. How are children learning? - traces the evolution and dynamics of group learning. It highlights the influence of social networking and discusses the characteristics of shared public learning.

\section{Why are children learning on the computer?}

One important determinant of children learning at the "hole in the wall" computers is their maturity level, in other words, age and preparedness towards learning determines why children come to the computers to learn.

Our observations show that the age range of children visiting and learning at "hole in the wall" computers is 8-14 years. This specific age range is likely to be related to the readiness of the child to learn. For any learning to take place at this young age, the child must have the necessary mental and physical repertoire to do so. They must have the necessary sensorimotor and cognitive systems in place before they can learn anything from the environment that they live in. Readiness and preparedness of the child helps explain the lower end of the age range, that is, why eight year olds visit the learning station to learn computing skills. The upper end of the age range of children who visit the learning station is 14 years.

Let us understand this better with an illustrative example: Manish is 14 years old and studies in class 7 . He used to go to the learning station with his friends, but now shows disinterest and seldom visits. Manish stated, "Man bhar gaya he", meaning that he did not go to the learning station because the learning station no longer fascinates him. He now finds it boring and gets restless. He has not visited it for the last one year. He also reports that he does not remember much about computers, but is keen to learn its operations. On being prodded for reasons as to why he does not visit the learning station Manish reports that he had to leave as younger children visited the learning station, "I used to feel old." A friend of Manish revealed that the younger boys would tease him whenever he did visit the learning station. The embarrassment of being too old to visit the learning station acted as a deterrent for Manish to continue learning computing skills. It is important to note that Manish reported that he did go to school, but remained free most of the time. The desire to learn computers was present but his age became a restraining factor in visiting the learning station.

Manish's case is one such example from the many that have been cited by the children of his age. His case indicates one of the main reasons why children stop visiting the learning station as they reach the age of 14 years. This could be linked to the adolescent period and its related issues and problems. Maybe, because computers are out in the public sphere, children around the age of 13-14 years feel that they are too old to visit a public space. There is a possibility that they can learn behind closed doors. On the one hand, children start visiting the learning station when they are about 
7-8 years old. This is when they are ready to learn and explore the environment and the world around them.

The second major determinant is "hole in the wall" computers providing novel stimuli for the children. Surprise plays a significant role in the child's ability to perceive and react to novel stimuli as adaptively as possible. Surprise is an important determinant of the complex phenomenon of attention. Attention plays an important role in cognitive achievement for it has important cognitive elements in the form of anticipations and expectations (Piaget, 1952). Piaget observed that surprise plays a role in the processes controlling cognitive development; children accommodate and assimilate by attending to the novel situation. Attention to a stimulus then is an important antecedent in learning, for curiosity behaviour brings the child into fresh contact with new stimuli.

For example, Kiran Kumar, 10 years old, wrote in his diary: “Today, I opened kid match. Here, I have to match the pictures. First, I took the arrow on the picture then pressed the red mouse. Then I took it in to another picture. After finishing the game, I heard some music it is very sweet to listen. Then, I opened Hindi songs by typing www.apbkdh.com and pressed enter key. I learnt this myself. Two pictures appeared, I took the first picture and clicked the red mouse. A list of songs appeared. I clicked on the first song and after some times I heard the song and it is excited me very much". Phrases like "very sweet", "it is excited me" indicate that whenever the children opened a new application, they experienced a sense of novelty and surprise, which was positive and gave way to feelings of happiness and thrill. This led them to continue exploring.

The attractions of the "hole in the wall" computers, such as novelty and surprise as attention getting, are also reinforcing in the sense that they instigate, mediate and maintain behaviour; stimulus complexity and reactions to it in terms of multi-sensory channeling; affective fall out in terms of joy, excitement, and the desire to master the challenge provided by the new stimulus ("hole in the wall" computers) by adopting varied learning strategies and collaborative networking. These are salient factors that go on to play a relevant and crucial process in learning.

\section{How are children learning?}

The next important finding of this paper is an insight into how children are learning. Learning at "hole in the wall" computers takes place through a sequence of stages of learning. These are based upon RCs observations:

- A group of children work at the computer with intense excitement (Figure 1).

- They attend to the novel situation of exploring on the computer. As they do not know how to operate the computer, very often, due to a group of children attempting to explore the mechanics of the situation, they find it difficult to proceed. For example, during the first week the computer hangs because all the children are pressing on the keyboard simultaneously. Gradually a fluid and flexible group emerges that operates on the computer and learns through any one or combination thereof - through the methods of trial and error, exploration, incidental learning, observation or seeking computer information knowledge from others. 


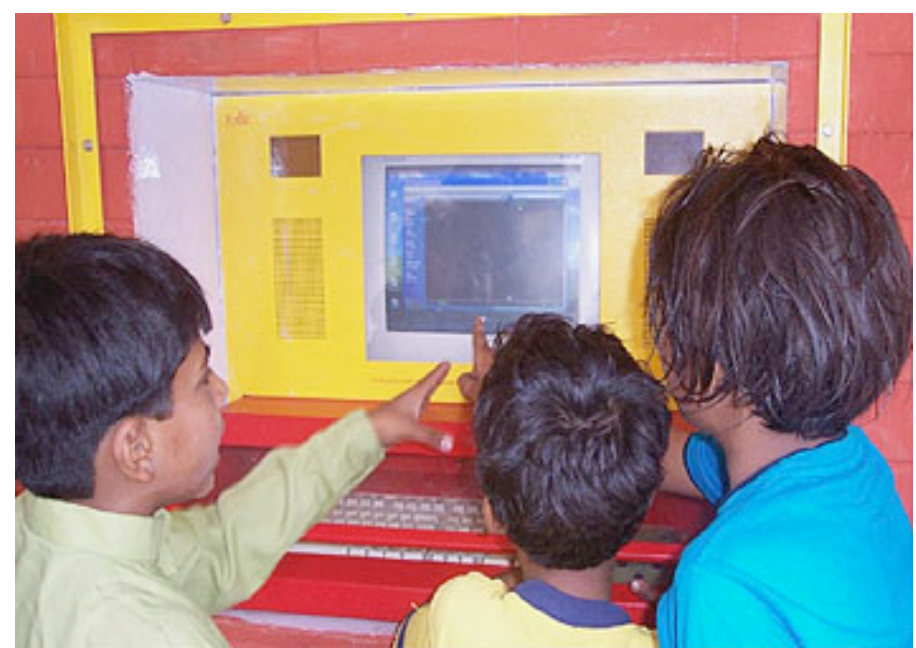

Figure 1: Children working at one of the learning stations

The strategy each child adopts is a combination of these methods. Any new discovery leads to the next stage.

- An important aspect is that this group is open to learning and influences from outside, meaning that it absorbs any relevant information from significant others, who are more knowledgeable than themselves. Further, since the group is flexible, any child can join or leave the group, although the function and structure of the group remains the same. This is called social networking.

- Social networking is the process of linking, that is, the way a child connects with another to create, construct a network/ social group he or she can then come to depend upon in order to obtain/acquire information, as and when he or she needs it.

- Rehearsal of any activity is an essential precursor to permanent learning.

- Rehearsal of activities at the computer leads to more discoveries and breakthroughs in gaining more and more information about computer usage.

- The information filters in all directions from one child to the other. The snowballing effect touches a large number of children.

- Each child learns from the others, whether a friend, brother, sister or even a stranger, and also tutors and guides these very same others. It is this new feature, of the child as learner and teacher that needs to be investigated in detail, so as to understand the mechanics of the computer learning environment at the "hole in the wall" computers.

- After some time a stage is reached where no new learning seems to take place. It is as if a particular limit has been reached. At this point, intervention is likely to make further computer learning possible.

At a micro-level, it is important to understand the "how" phenomena of learning. Firstly, the "hole in the wall" computers takes place in a natural setting that is, in a public place that is open to any and every child. Any child is free to go, at any time, alone or with a group of friends, a brother, a sister, an acquaintance, and work for any length of time. Based on children's diaries and parental observations, the range of time spent on the computer varied from a minimum of 5 minutes to a maximum of 30 minutes per visit. 
The study indicated important aspects of the "hole in the wall" environment:

i. The age group of the children varied from 8-14 years. This wide variation in age provided a diversity that aided learning. The more knowledgeable taught the less knowledgeable, thus every child had something to learn and teach.

ii. The size of the working group of children was about 4-7 children; the group size was large enough to allow diversity of reactions and inputs of knowledge, yet small enough for individual participation.

iii. Children came to the "hole in the wall" computers and left after some time; later coming back to work again at the computers.

These above aspects of the children's environment combine to provide the following crucial features:

- The personal and attitudinal attributes of the children visiting the kiosk are of diverse nature. This variant group, where each child has divergent attributes, is of vital importance for "hole in the wall" computer learning to take place.

- Each child absorbs computing skills at different rates of learning adopting his or her own learning strategies.

- Each child because of his or her different attributes, and particularly different levels of knowledge about computing skills, on each visit to the learning station, contributes in an important way to the overall learning process, for self as well as the others frequenting the learning station.

- Each child with his or her level of computing knowledge enhances learning by either practising on the computer as well as observing other children operating on the computer. At the same time, the child acts as a 'teacher' to other children who have yet to acquire some computer knowledge.

- This process of self learning and teaching is unique and distinctive to "hole in the wall" computer learning, and can be said to be the core strength of the continuing learning process at "hole in the wall" computers.

- The children in the "hole in the wall" computer setting not only learn but also share this with other children at the learning station. Thereby, enhancing the value of the learning.

We observed that the gap between the learner and the expert disappeared as all individuals are considered to be experts in some capacity in the "hole in the wall" computer setting. There is a collective dimension to this approach, as learning often takes place in teams, groups and shared across the group.

Secondly, the "hole in the wall" computer setting encourages shared knowledge amongst children. The heterogeneous group at a "hole in the wall" computer goes on to play the crucial role of providing a platform for each child to draw upon in times of need of any information. It is the act of sharing necessary information that enables the evolutionary development and continuous progress of the learning environment. Learning at "hole in the wall" computers provides a context within which information is not given by adults but by peers, siblings and friends. This reveals an important feature. The child gets information that is just sufficient to learn computing skills. The child imbibes this bit of information and then goes on to take more relevant information, in this way the process continues. The availability of peers or others enables each child to draw upon the required information. In a traditional setting, adult caregivers normally regulate the dialogue with children, but with "hole in the 
wall" computers we note how peer group learning takes place. A key phenomenon in such interactions is that children maintain dialogues between each other. Jerome Bruner and his colleagues called this scaffolding. It takes place within a child's zone of proximal development. Scaffolding and dialogue are especially useful concepts or frameworks for shared learning in public places.

Thirdly, even though learning takes place within a shared setting, where children draw upon each other for information about computers, another emerging feature is self regulated learning. Each child has to learn to take responsibility for monitoring, adjusting, self questioning, and questioning each other. Such self regulating activities are critical for children to learn today, and they are much better learned within a group that shares responsibility for learning. Monitoring is an essential feature as it reviews the child's progress towards his or her goals. Adjusting refers to changes children make, based on monitoring, in what they are doing to reach their goals.

Ravi, 10 years, said, "I wanted to open Internet but could not. I asked my friend Ramesh to help, but he too did not know. So, I then asked Laxmi, a girl standing next to me to help me and she helped me. I now have become friends with Laxmi, as she helps me at the computer".

From the above example, it is observed that Ravi switched to Laxmi when he found that his friend Ramesh could not help him. When children did not learn anything new from their group, they changed their group or approached another child to glean some new information, so as to progress in the activity they were doing on the computer.

Interviews with children who frequented the learning station indicate one aspect continuously and repeatedly. All children, across all sites in the country, reported that they enjoyed the act of working with computers. This was expressed in various forms, for example, 'It is fun to be here (at the learning station)'; 'I enjoy working here'; 'I feel good coming here (at the learning station); 'feeling of pleasure'. These inputs, "fun, enjoyment pleasure and feeling good" relate to two important aspects present in any learning situation, emotions and motivation. These two aspects are core elements in any learning situation.

One boy wrote:

- Computer is beneficial for us.

- Once we start to work on the computer there are lots of good things that we learn.

- In today's world, if we do not use the computer, then nobody can learn anything.

- Anyone who has learnt computers will become a great person, someday.

In essence what this boy meant to say was that "computers are a necessity today and we learn a lot from computers". Children report that they want to learn computers because it will help them in their studies and help them achieve better grades. These aspects relate to external or extrinsic reasons for learning, that is, learning as a step towards something else. On the other hand, some children also indicated intrinsic reasons, that is choosing to learn something for the pleasure of learning itself. Such as, wanting to learn because "I want to"; "it makes me feel good"; "I like it". Such aspects reflect that the child learns because the learning experience itself is a positive, and the child is driven by his or her search for growth and satisfaction. Some children reported reactive learning that is, choosing to learn because others, a younger or elder brother, or sister, or friend, were learning. Whereas, others reported proactive learning, that is, 
choosing to learn because of the desire to know what was happening in the environment and to keep up to date with it. These children said, "Computers are a means to keep abreast with what is happening in current times"; "I will be able to grow well in future"; "I will do well in life". Most children gave reasons indicating a combination of reactive and proactive, and intrinsic and extrinsic, motivating reasons for visiting the learning station.

\section{Discussion}

From the results, it is clear that children have learnt on their own using unsupervised "hole in the wall" computers. This has provided us with insights into the dynamics of the group learning process in this environment.

\section{Maturity}

Age of the child is seen as a primary determinant to learning. Children need to reach the critical age; they must be physiologically prepared and ready to learn before any specific learning can take place. The concept of preparedness can be can be understood as a continuum; at one end is the limited number of responses at birth but as the child grows and matures, the child becomes capable of making diverse type of responses. Thus, as the child matures in age, physiological and psychological readiness helps the child to evolve as a learner (Cratty, 1986). Hence, the age group that current research has revealed indicates that eight year olds are mature enough to learn basic computing skills. It can be assumed that the necessary sensorimotor skills and cognitive systems have reached the required maturity for the child to learn computing skills.

\section{Social networking and learning methods}

"Hole in the wall" computers encourage the emergence of group processes or social networking and, this in turn enables the manifestation of learning methods and strategies used by groups of children to attain basic computing skills. The methods identified are primarily observation and modeling, trial and error, accidental discovery, and self discovery. Groups of children make use of these methods, singly or in combinations. The present research indicates the influence of social interaction and collaboration amongst children, and in turn on the cognitive development of children.

The notion that social interaction is important for a child's cognitive development is not new. Piaget and Vygotsky for example, strongly emphasised that social interaction plays a crucial role and promotes various aspects of cognitive development. Bandura's $(1969,1986)$ work has shown the prevalence of social modeling that children can learn through observation, without any direct incentive and that learning gains persist over time. Termed as vicarious learning, it involves active constructions of symbols and Bandura (1969) emphasised that cognitive coding is a learned skill that is cued by environmental stimuli. In this way, it is not only the objective properties of the events, but also the social environment and interaction with it that contributes to learning. Thus, "hole in the wall" settings provide the children with the necessary learning environment for learning, in this case, learning basic computing skills.

This study further indicates that children prefer to learn from their peer group. Being at a similar stage of development, children speak and understand the nuances of their peer 'group language'. Such a strategy is helpful because these children, from whom 
they are taking help and collaborating, serve as a more helpful competence model, something within their reach. Adults or teachers do provide a learning context but being a highly skilled and knowledgeable set up, that is, it is a much higher competence model, and hence may be unattainable by the child. Yes, ideals are required to motivate the child to high achievements. But where certain types of learning are concerned, they may learn better from same aged children. This has been established by Vygotsky's concept of "zone of proximal development" (ZPD). Much of the discussion about ZPD has assumed that, in order to learn, the young novice needs the assistance of a more expert person who participates with him or her in the activity. Certainly, parents and teachers are the most important providers of guidance and assistance in relation to the child's learning, in early childhood and even beyond. But they are not the only significant others in this respect. Vygotsky made this clear when he wrote: "learning awakens a variety of internal developmental processes that are able to operate only when the child is interacting with people in his environment and in cooperation with his peers" $(1978$, p.90).

\section{Social networking and self organisation}

Learning at "hole in the wall" computers constitutes a novel situation where children learn in the absence of a teacher, instructor or tutor. The absence of a teacher or instructor at the computer learning station means that children learn to guide themselves and others in learning basic computing skills. Collaboration amongst the children enables them to attain some computer literacy. Collaboration is an essential feature of any type of learning in the real world. Vygotsky's concept of ZPD has amply stated this aspect. Vygotsky describes it as "the distance between the actual development level as determined by independent problem solving and the level of potential development as determined through problem solving under adult guidance or in collaboration with more capable peers" (Vygotsky, 1978). In other words, a student can perform a task under adult guidance or with peer collaboration that could not be achieved alone. The ZPD bridges a gap between what is known and what can be known and Vygotsky claimed that learning occurred in this zone. Children need scaffolding, as provided by others to grow and develop. Scaffolding and reciprocal teaching are effective strategies to access the zone of proximal development. (Vygotsky 1930-1935; 1978).

In a traditional classroom, the teacher plays the vital role as information giver and is the expert who controls the flow of information; knowledge flows one way from teacher to student. In contrast, the metaphor for public learning is shared knowledge. The teacher has vital knowledge about content, skills, and instruction, and provides that information to students. However, shared public learning builds upon the knowledge, personal experiences, interactions, strategies, and culture that children bring to the learning situation. The perspectives, experiences, and backgrounds of all children are important for enriching learning at the "hole in the wall" computers.

\section{Motivators for learning}

Important characteristics of behaviour, as indicated by children operating "hole in the wall" computers, from which motivation can be inferred, include:

- Initiative for starting some activity, that is, visiting the learning station and working on the computer. 
- Preference in favour of one activity that is, visiting the learning station even though other activities are available.

- Persistence and continuity of an organised pattern of activities towards a relevant goal, that is, the repeated actions on the part of children to visit the learning station and the repetition of learnt operation on the computer.

- Vigour and strength of an activity in the course of pursuing a goal.

- High rate of learning, as indicated by the learning curve for icons (Dangwal et al., 2005).

\section{Conclusion}

Learning at "hole in the wall" computers in a shared public space constitutes a natural learning environment. The following aspects are salient at the individual level:

- The natural learning style of young children. Children are curious by nature, having a natural instinct to make sense of the world around them. The need to explore on their own is a strong motivating aspect, which provides the impetus to forge ahead in learning. In a classroom situation children are often passive learners, but given a computer in a natural setting, children come forth as active learners.

- Children not only observe the world but also want to operate it, in terms of touching, breaking, feeling, in short, trying to make sense of the world around them. In order to understand the world around them, they explore, at times on their own, at times with peers.

- While working at a computer children are not afraid to make mistakes. They are in no hurry; there is no shame or fear and pressure of evaluation. Without the negative connotations, as are present in any structured educational classroom setting, there is no right or wrong, good or bad. Children learn at their own pace.

- Children can learn from their own mistakes. Either by trial and error or by observing others, or by asking any one more knowledgeable.

- Finally, it can be stated that children are not passive learners. If given a chance they can operate upon the environment and "learn" without being under the pressure to "learn".

\section{Learning environment}

We as adults grow up to be taught to differentiate between play and work as two discrete departments, each to be cultivated in an individual manner. As children, we are taught not to play while we are at work. Interestingly, children learn the ropes of life through the system of play while interacting with their caregivers. Two of the aspects that emerge as important in the "hole in the wall" setting are:

- Learning of computing skills through active participation at a collaborative level. It is clearly evident that children adopt a collaborative method of learning that promotes sharing and distribution of expertise.

- Computers have attributes of a 'scaffolding' tool, enabling young children to learn basic computing skills in a social environment.

In conclusion, "hole in the wall" research reveals evidence of progression and development of learning in children, as a result of an implementation of technology. The present paper highlights that if technology is to influence teaching and learning, then the close link between the two domains needs to be studied, analysed and 
documented. The current paper is a contribution towards better understanding of an interaction between technology infrastructure (computers) and a social and educational infrastructure.

\section{References}

Bandura, A. (1969). Principles of behavior modification. New York: Holt, , Rinehart \& Winston.

Bandura. A. (1986). Social foundations of thought and action: A social cognitive theory. New Jersey: Prentice Hall.

Cratty, B. J. (1986). Perceptual and motor development in infants and children. 3rd ed. New Jersey: Prentice Hall.

Dangwal, R., Jha, S., Chatterjee, S. \& Mitra, S. (2005). A model of how children acquire computing skills from hole-in-the-wall computers in public places. Information Technologies and International Development, 2(4), 41-60. [verified 12 May 2008] http: / / www.mitpressjournals.org/ doi/ pdfplus / 10.1162/154475205775249319

Education Guardian (2000). Slum children get free Internet access. 17 October 2000. [verified 12 May 2008] http:/ / education.guardian.co.uk/Distribution/Redirect_Artifact/0,4678,0-383459,00.html

Frontline/World (2002). Kids-eye view: Looking through the hole in the wall. Frontline/World, October. [verified 12 May 2008] http:/ / www.pbs.org/frontlineworld/stories/india/kids.html

Inamdar, P. (2004). Computer skills development by children using 'hole in the wall' facilities in rural India. Australasian Journal of Educational Technology, 20(3), 337-350. http: / / www.ascilite.org.au/ajet/ajet20/inamdar.html

Mitra, S. (2003). Minimally invasive education: A progress report on the "hole-in-the-wall" experiments. British Journal of Educational Technology, 34(3), 367-371.

Mitra, S., Dangwal, R., Chatterjee, S., Jha, S., Bisht, R. S. and Kapur, P. (2005). Acquisition of computing literacy on shared public computers: Children and the "hole in the wall". Australasian Journal of Educational Technology, 21(3), 407-426. http: / / www.ascilite.org.au/ajet/ajet21/ mitra.html

Mitra, S. \& Rana, V. (2001). Children and the Internet: Experiments with minimally invasive education in India. British Journal of Educational Technology, 32(2), 221-232. http:/ / www.holein-the-wall.com/docs/Paper02.pdf

Piaget. J. (1952). The origins of intelligence in children. New York: International Unilever Press.

Vygotsky, L. S (1986). Thought and language. (A. Kozuiln, Trans.) Cambridge, MA: MIT Press. (Original work published 1934).

Vygotsky, L. S. (1978). Mind in society: The development of higher mental processes. Cambridge, M.A: Harvard University Press. (Original works published 1930, 1933 and 1935).

Ritu Dangwal $P h D$ and Preeti Kapur

Centre for Research in Cognitive Systems, NIIT Institute of Information Technology

8, Balaji Estate, Sudarshan Munjal Marg, Kalkaji, New Delhi - 16, India

Email: ritud@niit.com 